\title{
SPECIFIC IMMUNE RESPONSES INDUCED BY MULTI-EPITOPE DNA DERIVED FROM MYCOBACTERIUM TUBERCULOSIS DOSR ANTIGENS
}

\author{
JALE MORADI $^{1}$, MARYAM IZAD ${ }^{2}$, MINA TABRIZI $^{3}$, NADER MOSAVARI $^{4}$, \\ BEHNAZ ESMAEILI $^{2}$ and MOHAMMAD MEHDI FEIZABADI ${ }^{1,5 *}$ \\ ${ }^{1}$ Department of Microbiology, School of Medicine, Tehran University of Medical \\ Sciences, Tehran, Iran \\ ${ }^{2}$ Department of Immunology, School of Medicine, Tehran University of Medical \\ Sciences, Tehran, Iran \\ ${ }^{3}$ Department of Medical Genetics, School of Medicine, Tehran University of Medical \\ Sciences, Tehran, Iran \\ ${ }^{4}$ Department of Tuberculosis, Razi Vaccine \& Serum Research Institute, Karaj, Iran \\ ${ }^{5}$ Thoracic Research Center, Imam Khomeini Hospital, Tehran University of Medical \\ Sciences, Tehran, Iran
}

(Received: 2 November 2017; accepted: 27 November 2017)

\begin{abstract}
One third of the world population are latently infected with Mycobacterium tuberculosis and are at the risk of reactivation of tuberculosis (TB). The most effective strategy for control of TB worldwide is the development of a vaccine that inhibits progression of latent TB to active infection. In this study, two optimized constructs consisting of multi-epitopes DNA derived from three latency antigens Rv2029c, Rv2031c, and Rv2627c fused with or without light chain 3 (LC3) are synthetized. The immunogenicity effectiveness of two DNA constructs was evaluated in the mouse model. LC3-fused multi-epitope DNA construct induced strong specific Th1 immune responses with high increase in IFN- $\gamma^{+} \mathrm{CD} 4^{+}$and $\mathrm{IL}-2^{+} \mathrm{CD} 4^{+} \mathrm{T}$ cell populations (both with $p<0.0001)$ and IFN- $\gamma^{+} \mathrm{IL}^{+} 2^{+} \mathrm{CD}^{+} \mathrm{T}$ cell population $(p<0.0001)$ compared with empty vector, BCG, and multi-epitope DNA construct groups. The LC3-fused construct induced IFN- $\gamma^{+} \mathrm{CD}^{+} \mathrm{T}$ cell population $(p<0.0001)$ compared with empty vector and BCG groups but could not induce the $\mathrm{T}$ cell population compared with construct without LC3. Importantly, LC3-fused DNA construct did not induce epitope-specific IL- 4 and IL- 10 from $\mathrm{CD}^{+}$and $\mathrm{CD}^{+} \mathrm{T}$ cell populations. The results indicated that $\mathrm{LC} 3$-fused multi-epitope DNA construct has a potential to be investigated for future development of a new TB vaccine.
\end{abstract}

*Corresponding author; E-mail: mfeizabadi@tums.ac.ir 
Keywords: Mycobacterium tuberculosis, LTBI, vaccine, DosR regulon, LC3, specific $\mathrm{T}$ cell response

\section{Introduction}

Tuberculosis (TB) is one of the most important infectious diseases in the world caused by the Mycobacterium tuberculosis complex [1]. TB alongside HIV ranks as leading cause of death among infectious diseases, globally. Approximately, 1.4 million of TB patients died in 2015, of which 0.4 million were HIV-positive [2].

Increase in prevalence of multidrug-resistant (MDR) TB and slow progress in new drug development highlighted the urgent need for developing an effective vaccine [1]. BCG is a neonatal vaccine that protects against disseminated $\mathrm{TB}$ in children but it has variable efficacy against pulmonary TB $[3,4]$.

Two billion people worldwide are latently infected with $M$. tuberculosis, of which $5 \%-15 \%$ are at the risk of reactivation of TB [2]. Therefore, postexposure vaccine strategy that inhibits progress of latent TB infection (LTBI) to active TB will be an effective strategy to control TB worldwide [5-7].

DosR regulon consists of nearly 50 genes expressed in hypoxic conditions present in the dormancy stage of infection [8, 9]. Various studies showed that among DosR regulon antigens, Rv2029c, Rv2031c, and Rv2627c are strong inducers of $\mathrm{T}$ cell-mediated immunity and are also highly recognized in tuberculin skin test positive (TST+) in individuals [10-13].

Among different types of $\mathrm{T}$ cell populations contributed to the TB immune response, antigen-specific $\mathrm{CD}^{+}{ }^{+} \mathrm{Th} 1$ and $\mathrm{CD} 8^{+} \mathrm{Tc} 1$ cells have important roles in protection against TB [14-16]. Therefore, strong induction of aforementioned $\mathrm{T}$ cells has an important characteristic in designing the TB vaccine candidates. M. tuberculosis predominantly reside in phagosome where the antigens were processed for major histocompatibility complex class II (MHC-II) presentation and CD4 T cells recognize epitopes of M. tuberculosis antigens by MHC class II molecules [17].

Autophagy acts as an immune mechanism, defending against intracellular micro-organism, such as M. tuberculosis [18]. The autophagy system contributes to the antigen processing through lysosomal degradation to enhance the MHC class II presentation [19]. Microtubule-associated protein light chain 3 (LC3) molecule is an important key factor of autophagy system, which reside in cells in inactivated form named LC3A and will be processed by protease activity of Atg 4 to liberate a carboxy-terminal glycine residue and LC3B as activated form [20]. Autophagosome couples with LC3B and then fuses with MHC class 
II-containing compartments to present the antigens to MHC class II [21]. Thus, autophagy targeting strategy increases CD4 T cell responses, which eventually could be an effective strategy in TB vaccine development.

In the previous study, a multi-epitope DNA with or without LC3 was designed and analyzed [22]. In this study, codon-optimized genes were synthetized and DNA constructs were created and the immunogenicity of DNA constructs was evaluated in $\mathrm{BALB} / \mathrm{c}$ mice.

\section{Materials and Methods}

\section{Design and construction of DNA plasmids}

In our previous study, MHC class I and II binding epitopes of three latencyassociated antigens Rv2029c, Rv2031c, and Rv2627c were predicted (Table I). MHC class I and II epitopes were fused together tandemly with appropriate linkers to avoid interferences in epitope processing (Figure 1A). In another design, LC3 was directly fused to the C-terminus of the multi-epitope peptide [22]. In this study, the latest peptides were utilized for reverse translation and codon optimization. Finally, some additional sequences were added (Figure 1B and 1C). The final sequences were synthesized (Generay biotechnology, China), digested by BamHI and XhoI restriction enzymes, and inserted to the pcDNA3.1(+) myc-HisC (Invitrogen) to create the multi-epitope DNA and LC3 multi-epitope DNA constructs. The synthesized multi-epitope sequence without LC3 was digested at NcoI and XhoI restriction sites and inserted to pET-21d(+) (Novagen, USA) to make a construct, acting as a recombinant prokaryotic expression vector. Recombinant plasmids were verified by restriction enzyme digestions and sequence analysis. Finally, the constructs were purified by High Pure Plasmid Isolation Kit (Roche, USA).

Table I. Selected MHC class I- and II-binding epitopes

\begin{tabular}{|c|c|c|c|c|c|}
\hline \multicolumn{3}{|c|}{ MHC class I-binding epitope } & \multicolumn{3}{|c|}{ MHC class II-binding epitope } \\
\hline Protein & Epitope sequence & Position & Protein & Epitope sequence & Position \\
\hline \multirow[t]{2}{*}{ Rv2029c } & RYDPGGGGINVARI & $44-57$ & Rv2029c & LRGAAASAAFVVASG & $135-149$ \\
\hline & RFVLPGPSLTVAE & $115-127$ & & IPMTAVSGVGAG & $253-264$ \\
\hline \multirow[t]{2}{*}{ Rv2031c } & VDPDKDVDI & $60-68$ & Rv2031c & DKGILTVSVAVSEGK & $118-132$ \\
\hline & GSFVRTVSL & $96-104$ & Rv2627c & IGRMISPLSLTPLVP & $325-339$ \\
\hline Rv2627c & GPFMHTGLY & $27-35$ & & RFVQAALEQSGLLDA & $390-404$ \\
\hline
\end{tabular}


A

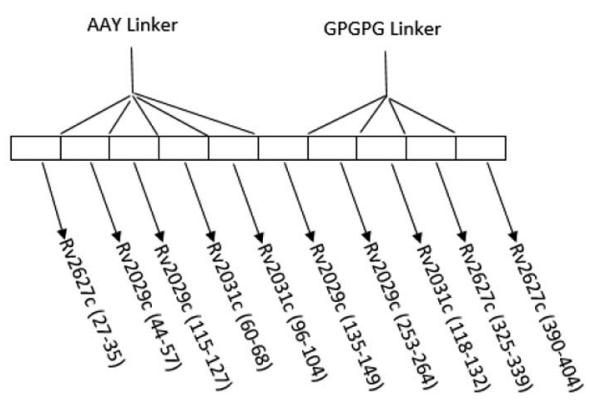

B

Kozak consensus sequence

\}
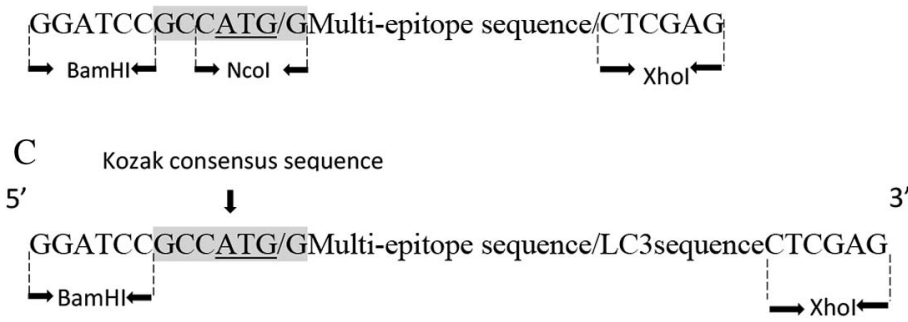

Figure 1. Structure of designed multi-epitope DNA sequence. (A) Schematic representation of MHC class I and II epitopes of antigens, joined by appropriate linkers, indicating the position of epitopes. AAY linkers were utilized for fusion of MHC class I-restricted epitopes and GPGPG linkers were applied to conjugate MHC class II-restricted epitopes. (B) Schematic representation of the synthesized DNA sequence including multi-epitope DNA sequence flanked by BamHI and XhoI restriction sites at $5^{\prime}$ and $3^{\prime}$ ends, respectively and kozak consensus sequence containing ATG start codon and NcoI restriction site. $\mathrm{G}$ in the +4 position of kozak sequence designed to be the first nucleotide of the multi-epitope sequence. (C) Schematic representation of the synthesized DNA sequence including multi-epitope DNA sequence which was fused directly to the LC3. Kozak consensus sequence showed in highlighted sequence and multi-epitope sequence placed between two slashes (/)

\section{Transfection and Western blot analysis}

HeLa cells were transfected with LC3-fused multi-epitope DNA and multiepitope DNA constructs using Lipofectamine 2000 Reagent (Invitrogen) according to the manufacturer's instruction. HeLa cells were seeded in six-well plates with Dulbecco's Modified Eagle Medium containing 10\% fetal calf serum and incubated in $37{ }^{\circ} \mathrm{C}$ in $5 \% \mathrm{CO}_{2}$-humidified chamber overnight. When cells reached $80 \%-90 \%$ confluency, $15 \mu \mathrm{L}$ of Lipofectamine was diluted to final volume of $150 \mu \mathrm{L}$, in Opti-MEM medium (Invitrogen). Also, $4 \mu \mathrm{g}$ of each DNA construct or empty plasmid was diluted to final volume of $150 \mu \mathrm{L}$ in Opti-MEM medium. 
Then, each diluted DNA construct or empty plasmid was added to the diluted Lipofectamine and incubated for $5 \mathrm{~min}$ at room temperature. The final volume of $300 \mu \mathrm{L}$ DNA/Lipofectamine mixture was added to each well. Two wells were considered as control, one well received $300 \mu \mathrm{L}$ of the diluted Lipofectamine without any DNA and the other well was left without adding any prepared reagent. Six-well plates were incubated for $72 \mathrm{~h}$ and subsequently cells were harvested, washed with phosphate-buffered saline (PBS), lysed with lysis buffer [Tris pH 6.8, sodium dodecyl sulfate (SDS) 15\%, glycerol, $1 \mathrm{M}$ dithiothreitol, bromophenol blue, and $\mathrm{ddH}_{2} \mathrm{O}$ ], and were centrifuged for $5 \mathrm{~min}$ at $15,000 \times g$. The cell lysates were run on $12 \%$ SDS-polyacrylamide gel electrophoresis (PAGE) and transferred to the polyvinylidene difluoride membrane (Roche) using the semi-dry blotting technique. The membrane was blocked with $5 \%$ skimmed milk for $3 \mathrm{~h}$ at room temperature. The membrane then probed with anti-His Tag (BioLegend, USA) antibody overnight at $4{ }^{\circ} \mathrm{C}$. Then, it was washed, probed with appropriate HRP-conjugated goat anti-rabbit IgG (Sigma-Aldrich, USA) for $1 \mathrm{~h}$ at $37{ }^{\circ} \mathrm{C}$ and visualized directly using SIGMAFAST 3,3'-diaminobenzidine (Sigma-Aldrich).

\section{Expression and purification of recombinant protein}

The recombinant pET-21d(+) vector was transformed into Escherichia coli BL21 (DE3) (Novagen) and induced with isopropyl $\beta$-D-1-thiogalactopyranoside (IPTG) for $6 \mathrm{~h}$. After IPTG induction, the cultured E. coli BL21 was centrifuged to collect bacterial cell pellets. The collected cells were lysed by lysis buffer $(35 \mathrm{mM}$ $\mathrm{NaH}_{2} \mathrm{PO}_{4}, 200 \mathrm{mM} \mathrm{NaCl}, 8 \mathrm{mM}$ imidazole, $\mathrm{pH}$ 8) for $30 \mathrm{~min}$. The lysates were sonicated as follows: $15 \mathrm{~s}$ pulses at $15 \mathrm{~s}$ intervals for five consecutive times. The sonicated cells centrifuged for $15 \mathrm{~min}$ at $10,000 \mathrm{rpm}$ and the supernatant was harvested. Then, the His-tagged multi-epitope protein was purified using the Ni-NTA column (Qiagen, USA) according to the manufacturer's protocol, identified by Western blotting as described before, and applied for in vitro stimulation of splenocytes which is a necessary step for cytokine detection in flow cytometry assay.

\section{Animal immunization}

Female BALB/c mice (6- to 8-week old) were immunized intramuscularly with $100 \mu \mathrm{g}(50 \mu \mathrm{g}$ per quadricep) of each DNA construct and/or empty vector as negative control. To assess the cellular immune response, mice were immunized three times (at 0,2 , and 4 weeks). The BCG-immunized mice were used as positive control in fourth group. BCG was injected subcutaneously once with a dose of $10^{6}$ 
CFU at the first immunization. Two weeks after the last injection, all mice were sacrificed and their spleens were aseptically removed. All animal studies were approved by the ethics committee of Tehran University of Medical Sciences.

\section{$T$ cell subset and cytokine release assay}

Splenic tissue was processed mechanically using a cell strainer to produce a single cell suspension. Mononuclear cells were separated from splenic cells by Lymphosep (Biosera, USA). Mononuclear cells were cultured at density of $2 \times 10^{6}$ cells $/ \mathrm{mL}$. This was triplicated in $1 \mathrm{~mL}$ of complete RPMI-1640 medium in 24-well plates. The cells were stimulated in vitro by $10 \mu \mathrm{g} / \mathrm{mL}$ of recombinant multi-epitope protein or with $\mathrm{CD} 3 / \mathrm{CD} 28$, as positive control. The cells that were cultured without any stimulation were considered as negative control. Cells were incubated at $37{ }^{\circ} \mathrm{C}$ in a humidified chamber with $5 \% \mathrm{CO}_{2}$ for $72 \mathrm{~h}$. After $66 \mathrm{~h}$, $1 \lambda$ brefeldin A ( $5 \mathrm{mg} / \mathrm{mL})$ (BioLegend) was added to each well to inhibit cytokine release. Finally, cells were harvested and washed with FACS buffer (PBS with $2 \%$ FBS). Cell surface staining was carried out using anti-CD4 Alexa Fluor 488 and anti-CD8 PE-Cyanine 7 (eBioscience, USA). Cells were washed, fixed, and permeabilized with Intracellular Fixation/Permeabilization Buffer (eBioscience). Intercellular cytokine staining was performed using anti-IFN gamma PerCp-Cyanine5.5, anti-IL-4 PE, anti-IL-10 antigen-presenting cell (APC) mAbs (eBioscience), and anti-IL-2 APC-Cyanine 7 (BD Biosciences, USA). Flow cytometry was performed using FACSCanto II (BD Biosciences) and at least 200,000 events were acquired. Finally, the data were analyzed by the Flow Jo software, version 7.6 (Tree Star Inc., Oregon, USA).

\section{Statistical analysis}

All data were expressed as mean $\pm \mathrm{SD}$. Data were statistically analyzed by one-way analysis of variance (ANOVA) with Tukey's post hoc multiple comparison test using the SPSS software, version 22 (SPSS Inc., USA).

\section{Results}

Eukaryotic expression of DNA constructs

HeLa cells were transiently transfected with the multi-epitope or LC3-fused multi-epitope DNA constructs to examine the effectiveness of expression of DNA constructs in vivo. The empty vector was applied as negative control. Western 
blotting showed that transfected HeLa cells expressed both the multi-epitope and LC3-fused multi-epitope proteins successfully. The 19 and $31 \mathrm{kDa}$ bands were observed in transfected cells with multi-epitope and LC3-fused multi-epitope DNA constructs, respectively. Meanwhile, no protein was detected in cells transfected with the empty vector (Figure 2A and 2B).

\section{Purification of recombinant protein}

Recombinant protein was expressed in prokaryotic system and was purified to be used for restimulation of mice splenocytes in vitro, required for flow cytometry assay. After the IPTG induction, recombinant protein labeling His-tag was purified by Ni-NTA column. SDS-PAGE and Western blot were performed to confirm the expression. Recombinant protein with the molecular weight of about $17 \mathrm{kDa}$ was observed as expected (Figure 2C).

\section{Induction of $T$ cell immune responses}

Based on the importance of the CD4 and CD8 T cell immune responses in protection against $M$. tuberculosis, we applied multicolor flow cytometry, gated lymphocyte population, and evaluated the percentage of specific IFN- $\gamma$ and IL-2producing $\mathrm{CD}^{+}$and $\mathrm{CD} 8^{+} \mathrm{T}$ cells in all experimental groups to evaluate stimulation of key cytokines in defense against TB. Next, we characterized the
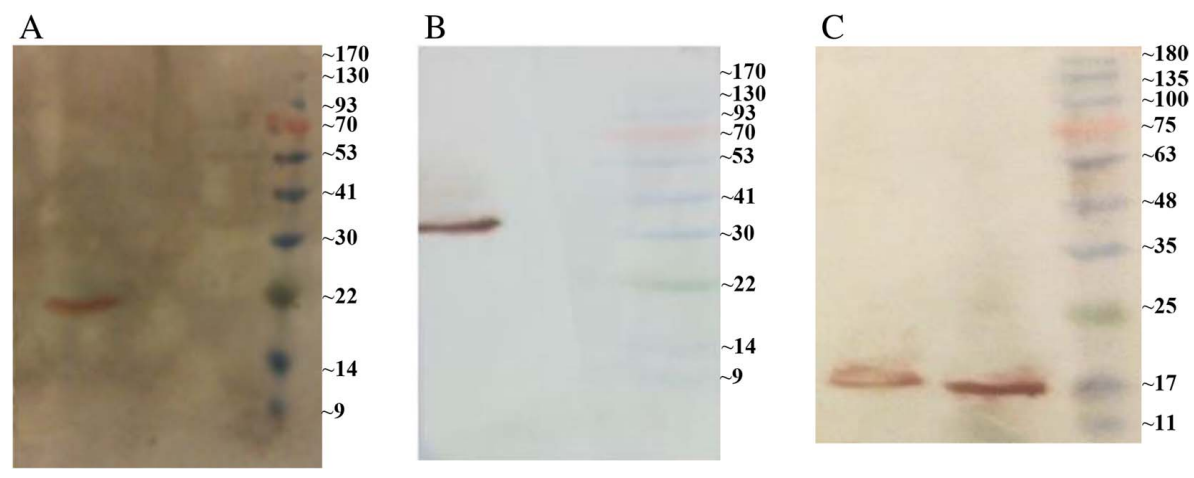

Figure 2. Western blot analysis. (A) Western blot of multi-epitope pcDNA3.1/ myc-HisC (lane 2), empty pcDNA3.1/ myc-HisC plasmid (lane 1) in HeLa cells, and prestained protein ladder 10$170 \mathrm{kDa}$ (lane M). (B) Western blot of LC3-fused multi-epitope pcDNA3.1/ myc-HisC (lane 2), empty pcDNA3.1/myc-HisC plasmid (lane 1) in HeLa cells, and prestained protein ladder 10$170 \mathrm{kDa}$. (C) Western blot of purified recombinant protein in E. coli BL21, first elution (lane 1), second elution (lane 2), and pre-stained protein ladder 10-180 kDa (lane M) 
co-expression of IFN- $\gamma$ and IL- 2 in $\mathrm{CD}^{+}{ }^{+} \mathrm{T}$ cells. We gated the $\mathrm{CD}^{+} \mathrm{T}$ cell population and analyzed the percentage of IFN $-\gamma^{+} \mathrm{IL}-2^{+} \mathrm{CD} 4^{+} \mathrm{T}$ cell population. Also, as an effective TB vaccine requires a decrease or no induction of IL-4 and IL-10 from $\mathrm{CD}^{+}{ }^{+}$and $\mathrm{CD}{ }^{+}{ }^{+}$cells; thus, we investigated the percentage of epitopespecific IL-4 and IL-10 from $\mathrm{CD}^{+}$and $\mathrm{CD}^{+} \mathrm{T}$ cell populations. The percentage of cytokine-producing $\mathrm{CD}^{+}$and $\mathrm{CD}^{+} \mathrm{T}$ cell populations were analyzed with oneway ANOVA in which descriptive statistics of the analysis are shown in Table II.

\section{Induction of specific CD4 ${ }^{+}$Th1 immune responses}

Mice immunized with LC3-fused multi-epitope DNA construct induced high percentage $(p<0.0001)$ of specific IFN- $\gamma^{+}$and $\mathrm{IL}-2^{+} \mathrm{CD} 4^{+}$T cells compared with multi-epitope DNA construct, BCG, and the empty vector groups (Figure 3). Mice immunized with multi-epitope DNA construct also induced high percentage of IFN $-\gamma^{+} \mathrm{CD}^{+}$T cells compared with BCG and empty vector groups $(p<0.0001)$. These results indicated that LC3-fused multi-epitope DNA construct has a potential to induce specific CD4 Th1 immune responses more than the other groups. However, multi-epitope DNA construct can stimulate acceptable IFN- $\gamma^{+}$ $\mathrm{CD}^{+}{ }^{+} \mathrm{T}$ cell response, it could not induce IL- $2^{+} \mathrm{CD} 4^{+} \mathrm{T}$ cells. Thus, LC3-fused multi-epitope DNA construct with effective induction of $\mathrm{IL}_{-} 2^{+} \mathrm{CD} 4^{+} \mathrm{T}$ cells is superior to multi-epitope DNA construct.

\section{Induction of specific $C D 4^{+}$Th2 immune responses}

Both multi-epitope and LC3-fused multi-epitope DNA constructs did not significantly induce IL-4- and IL-10-producing $\mathrm{CD}^{+} \mathrm{T}$ cells compared with the other groups (Figure 3). The BCG-immunized group stimulates high percentage of

Table II. Descriptive statistics of different CD4 and CD8 T cell subsets in immunized groups

\begin{tabular}{|c|c|c|c|c|}
\hline $\mathrm{T}$ cell subsets & $\begin{array}{l}\text { LC3-fused multi-epitope } \\
\text { DNA construct }\end{array}$ & $\begin{array}{l}\text { Multi-epitope } \\
\text { DNA construct }\end{array}$ & $\mathrm{BCG}$ & Empty vector \\
\hline $\mathrm{CD}^{+}{ }^{+} \mathrm{IFN}-\gamma^{+}(\mathrm{Th} 1)$ & $21.282 \pm 1.304$ & $10.910 \pm 0.994$ & $4.085 \pm 1.030$ & $2.415 \pm 0.202$ \\
\hline $\mathrm{CD}^{+}{ }^{+} \mathrm{IL}_{-} 2^{+}$(Th1) & $2.339 \pm 0.405$ & $1.106 \pm 0.270$ & $0.847 \pm 0.053$ & $0.686 \pm 0.136$ \\
\hline $\mathrm{CD}^{+}{ }^{+} \mathrm{IFN}_{-} \gamma^{+} \mathrm{IL}_{-} 2^{+}$ & $4.562 \pm 0.150$ & $1.279 \pm 0.301$ & $0.557 \pm 0.155$ & $0.560 \pm 0.310$ \\
\hline $\mathrm{CD}^{+} \mathrm{IL}^{+} 4^{+}(\mathrm{Th} 2)$ & $3.912 \pm 0.598$ & $3.695 \pm 0.510$ & $3.647 \pm 0.145$ & $3.697 \pm 0.433$ \\
\hline $\mathrm{CD}^{+}{ }^{+} \mathrm{IL}-10^{+}(\mathrm{Th} 2)$ & $4.943 \pm 1.092$ & $3.605 \pm 0.462$ & $5.967 \pm 0.247$ & $3.677 \pm 0.660$ \\
\hline $\mathrm{CD}^{+} \mathrm{IFN}^{-} \gamma^{+}(\mathrm{Tc} 1)$ & $2.459 \pm 0.220$ & $2.460 \pm 0.169$ & $0.303 \pm 0.108$ & $0.325 \pm 0.153$ \\
\hline $\mathrm{CD}^{+} \mathrm{IL}^{-} 2^{+}(\mathrm{Tc} 1)$ & $0.476 \pm 0.106$ & $0.527 \pm 0.098$ & $0.415 \pm 0.114$ & $0.427 \pm 0.154$ \\
\hline $\mathrm{CD}^{+} \mathrm{IL}^{-} 4^{+}(\mathrm{Tc} 2)$ & $0.796 \pm 0.172$ & $0.954 \pm 0.311$ & $1.222 \pm 0.409$ & $1.520 \pm 0.824$ \\
\hline $\mathrm{CD}^{+} \mathrm{IL}^{-10^{+}}(\mathrm{Tc} 2)$ & $0.539 \pm 0.797$ & $0.527 \pm 0.098$ & $0.386 \pm 0.123$ & $0.427 \pm 0.154$ \\
\hline
\end{tabular}


A

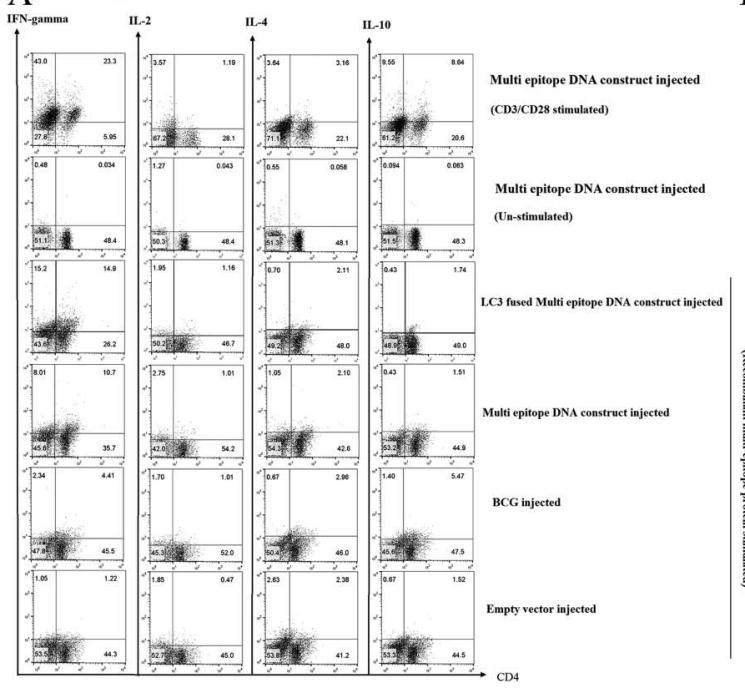

$\mathrm{B}$

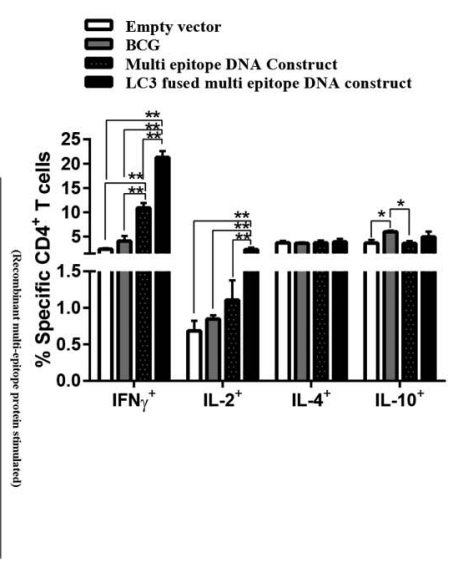

Figure 3. Flow cytometry analysis of epitope-specific $\mathrm{CD}^{+}{ }^{+} \mathrm{T}$ cells in BALB/c mice injected by LC3-fused multi-epitope DNA construct, multi-epitope DNA construct, BCG, and empty vector. (A) Representative flow cytometry data showing the percentage of epitope-specific CD ${ }^{+} \mathrm{T}$ cells in the total lymphocyte. (B) Bar graph showing the percentage of epitope-specific-IFN- $\gamma^{+}$, IL-2 ${ }^{+}, \mathrm{IL}_{-} 4^{+}$, and IL-10 ${ }^{+} \mathrm{CD} 4^{+} \mathrm{T}$ cells from LC3-fused multi-epitope DNA construct (black bars), multi-epitope DNA construct (dotted black), BCG (gray bars), and empty vector (white bars). Positive and negative controls are shown by splenocytes from designed DNA construct group, stimulated with CD3/CD28 and without any stimulation, respectively. Quadrants were set based on negative control group. The data are shown as mean $\pm \mathrm{SD}$. ${ }^{*} p<0.01 ;{ }^{*} p<0.0001$

IL-10-producing $\mathrm{CD} 4^{+} \mathrm{T}$ cells compared to the mice immunized with the empty vector and multi-epitope DNA construct $(p<0.01)$.

\section{Induction of specific bi-functional $C D 4^{+} T$ cell immune responses}

The results showed that LC3-fused multi-epitope DNA construct induced high percentage $(p<0.0001)$ of IFN $-\gamma^{+} \mathrm{IL}-2^{+} \mathrm{CD} 4^{+} \mathrm{T}$ cell population compared with multi epitope DNA construct, BCG, and empty vector groups (Figure 4). The multi-epitope DNA construct stimulates IFN- $\gamma^{+} \mathrm{IL}_{-} 2^{+} \mathrm{CD} 4^{+} \mathrm{T}$ cell population significantly $(p<0.01)$ compared with BCG and empty vector groups.

\section{Induction of specific CD8 ${ }^{+} T c 1$ immune responses}

Both LC3-fused multi-epitope and multi-epitope DNA constructs highly stimulate $(p<0.0001) \mathrm{IFN}-\gamma^{+} \mathrm{CD} 8^{+} \mathrm{T}$ cell population compared with the 
A

Multi epitope DNA construct injected
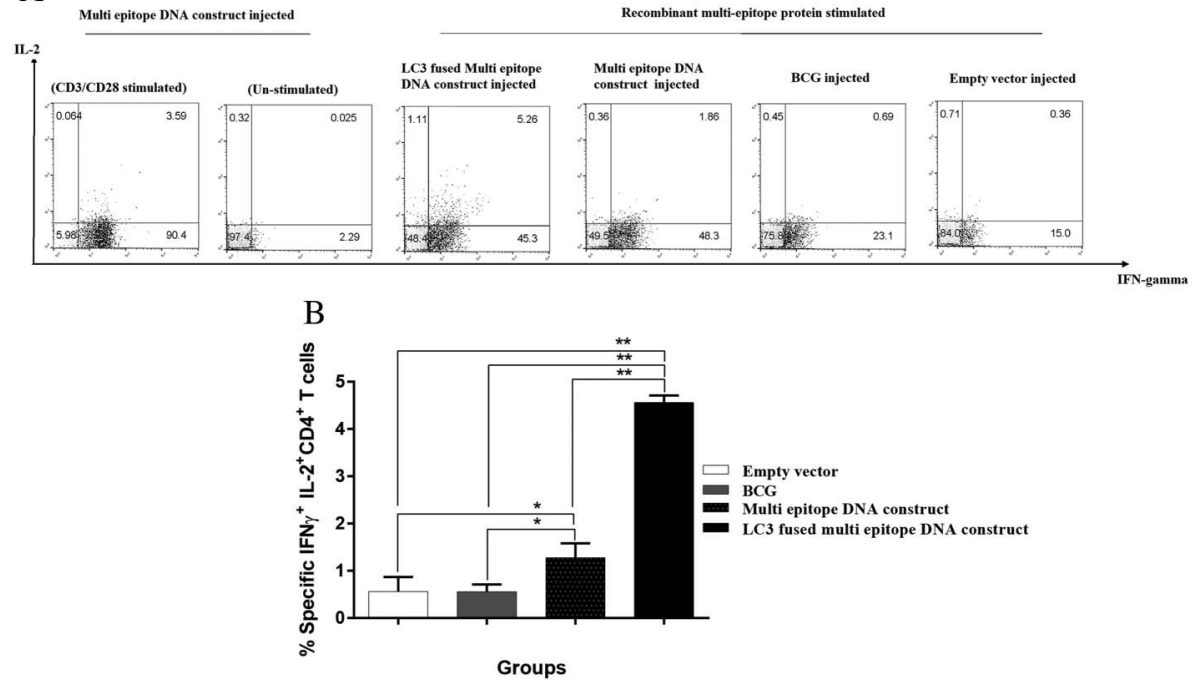

Figure 4. Flow cytometry analysis of epitope-specific bifunctional $\mathrm{CD} 4^{+} \mathrm{T}$ cells in BALB/c mice injected by LC3-fused multi-epitope DNA construct, multi-epitope DNA construct, BCG, and empty vector. (A) Representative flow cytometry data showing the percentage of epitope-specific IFN- $\gamma^{+}$IL-2 ${ }^{+} \mathrm{CD}^{+} \mathrm{T}$ cells in $\mathrm{CD} 4^{+} \mathrm{T}$ cells. (B) Bar graph showing the percentage of epitope-specific-IFN- $\gamma^{+} \mathrm{IL}-2^{+} \mathrm{CD} 4^{+} \mathrm{T}$ cells from LC3-fused multi-epitope DNA construct (black bars), multi-epitope DNA construct (dotted black), BCG (gray bars), and empty vector (white bars). Positive and negative controls are shown by splenocytes from DNA construct group, stimulated with $\mathrm{CD} 3 / \mathrm{CD} 28$ and without any stimulation, respectively.

Quadrants were set based on negative control group. The data are shown as mean \pm SD.

$$
{ }^{*} p<0.01 ;{ }^{* *} p<0.0001
$$

BCG and empty vector groups (Figure 5). But, there is no significant difference for stimulation of IFN- $\gamma^{+} \mathrm{CD} 8^{+} \mathrm{T}$ cell population between LC3-fused multiepitope and multi-epitope DNA constructs. Also, there was no meaningful difference for induction of $\mathrm{IL}-2^{+} \mathrm{CD}^{+} \mathrm{T}$ cell population between all groups.

\section{Induction of specific $C D 8^{+}$Tc2 immune responses}

We next analyzed the percentage of suppressive $\mathrm{CD} 8^{+} \mathrm{T}$ cell populations. The findings showed that there was no significant difference for stimulation of specific IL-4- and IL-10-producing $\mathrm{CD} 8^{+} \mathrm{T}$ cells in four groups of immunized mice (Figure 5). 


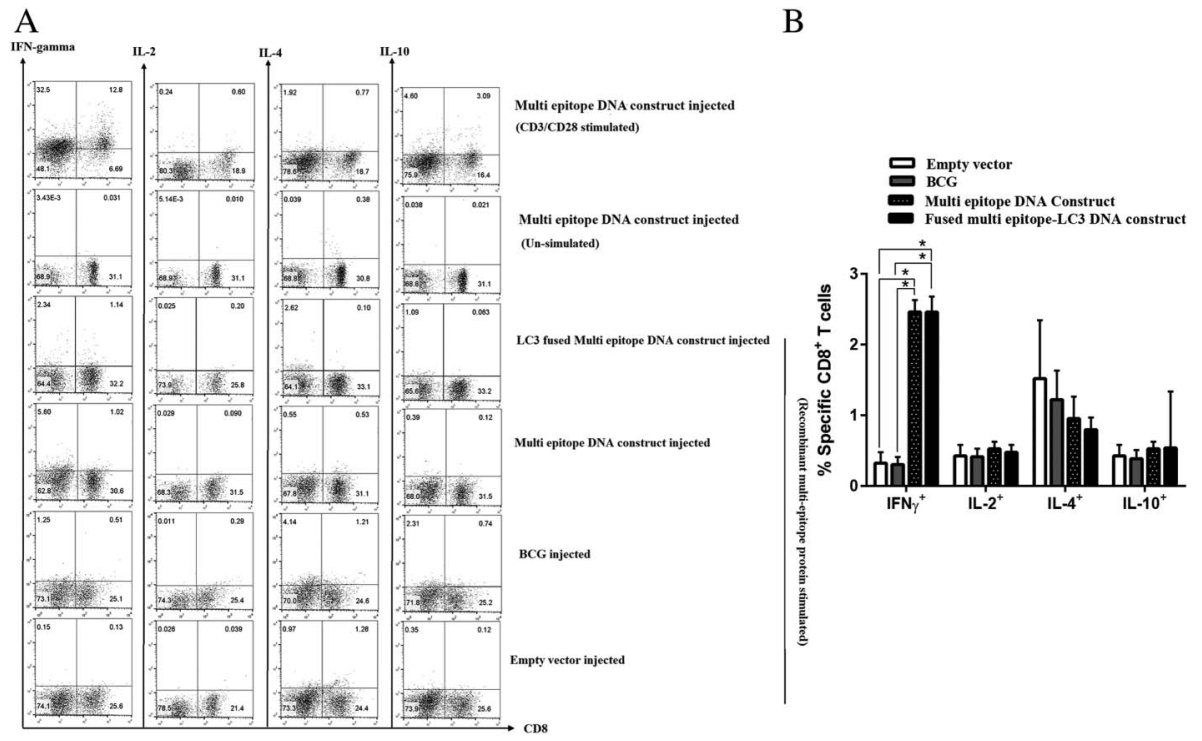

Figure 5. Flow cytometry analysis of epitope-specific $\mathrm{CD}^{+} \mathrm{T}$ cells in BALB/c mice injected by LC3-fused multi-epitope DNA construct, multi-epitope DNA construct, BCG, and empty vector. (A) Representative flow cytometry data showing the percentage of epitope-specific $\mathrm{CD} 8^{+} \mathrm{T}$ in the total lymphocyte. (B) Bar graph showing the percentage of epitope-specific IFN- $\gamma^{+}, \mathrm{IL}-2^{+}, \mathrm{IL}-4^{+}$, and $\mathrm{IL}-10^{+} \mathrm{CD}^{+} \mathrm{T}$ cells from LC3-fused multi-epitope DNA construct (black bars), multi-epitope DNA construct (dotted black bars), BCG (gray bars), and empty vector (white bars). Positive and negative controls are shown by splenocytes from DNA construct group that are stimulated with CD3/ CD28 and without any stimulation, respectively. Quadrants were set based on negative control group. The data are shown as mean $\pm \mathrm{SD} .{ }^{*} p<0.0001$

\section{Discussion}

Immunity against TB is a $\mathrm{T}$ cell-mediated immune response [23]. Currently, DNA vaccines are more attractive in TB vaccine development due to the induction of cell-mediated immunity against MTB infection [24]. There is high plasticity in this DNA vaccine design. It has been shown that fusion of multiple epitopes of several antigens elicits stronger specific $\mathrm{T}$ cell immune responses $[25,26]$. Also, DNA vaccines encoding MHC class I- and II-restricted epitopes induce both specific $\mathrm{CD}^{+}$and $\mathrm{CD} 8^{+} \mathrm{T}$ cell populations [27].

Although there are different $\mathrm{T}$ cells contribution in defense against MTB, most studies indicated that $\mathrm{CD} 4^{+} \mathrm{T}$ cells have essential role in protection against TB. Thus, applying strategies to enhance $\mathrm{CD}^{+} \mathrm{T}$ cell responses resulted in effective protection. T cells recognize epitopes that are presented by APCs via MHC molecules. CD8 T cells recognize endogenous epitopes that are presented by 
MHC class I molecules and CD4 $\mathrm{T}$ cells recognize exogenous epitopes that are presented by MHC class II molecules. Recent studies have proved that autophagy system has important role in presentation of antigens by MHC class II molecules [28].

In this study, we constructed a novel multi-epitope DNA construct by fusion of multiple MHC class I- and II-restricted epitopes of Rv2029c, Rv2031c, and Rv2627c antigens. Next, LC3 was fused to the multi-epitope DNA construct and the improvement and effectiveness of the immunogenicity was evaluated.

$\mathrm{T}$ cell immune response has protective roles against the MTB infection through $\mathrm{CD}^{+}{ }^{+} \mathrm{Th} 1$ and $\mathrm{CD} 8^{+} \mathrm{Tc} 1$ populations that produce key cytokines, such as IFN- $\gamma$, IL-2, or TNF- $\alpha$ [29]. IFN- $\gamma$ is an essential cytokine in resistance to MTB infection and is the most highly considered cytokine for characterization of Th1 immune response [30]. IL-2 also has important roles for secondary expansion of CD4 and CD8 T cells for generation of long-lived T cell populations [31, 32]. Previous studies have shown that in LTBI, the MTB antigen-specific CD4 ${ }^{+} \mathrm{T}$ cell populations are highly enriched in IFN- $\gamma^{+}$and IL- $2^{+}$[33] and MTB antigenspecific $\mathrm{CD}^{+}{ }^{+}$cell population are predominantly IL-2 ${ }^{-}$[34]. In this study, LC3fused multi-epitope DNA construct induced vigorous IFN- $\gamma$ and IL-2-producing $\mathrm{CD}^{+}{ }^{+}$and IFN- $\gamma$-producing $\mathrm{CD}^{+}{ }^{+}$T cells. Since our construct was designed based on latency-associated antigens for LTBI individuals, this profile for the CD4 ${ }^{+}$and $\mathrm{CD}^{+} \mathrm{T}$ cell population reflects appropriate immune response. Also, the multiepitope DNA construct induced acceptable IFN $-\gamma^{+} \mathrm{CD} 4^{+} \mathrm{T}$ cell immune response, but this construct could not induce $\mathrm{IL}-2^{+} \mathrm{CD}^{+} \mathrm{T}$ cell immune response. This result suggests a positive role for LC3 in enhancement of $\mathrm{CD}^{+}$Th1 immune response. On the other hand, as we expected, $\mathrm{CD}^{+} \mathrm{T}$ cell responses were not increased in LC3-fused multi-epitope DNA immunized group compared with multi-epitope DNA construct. Here, we speculate that LC3 has no role in MHC class I presentation. Mice immunized with BCG alone induced only low level of IFN $-\gamma^{+} \mathrm{CD}^{+} \mathrm{T}$ cells indicating that DNA constructs can induce more strong $\mathrm{T}$ cell responses than BCG alone. It is demonstrated that immunization with BCG cannot induce significant $\mathrm{T}$ cell responses to DosR regulon dormancy antigens [35]. Based on the results, DNA constructs in this study seem to be superior to BCG.

The capability to produce one, two, or three kinds of key protective cytokines (IFN- $\gamma$, IL-2, or TNF- $\alpha$ ) by an individual T cell endows the cell with the ability to be an effector cell, memory cell, or both [36, 37]. Therefore, CD4 ${ }^{+}$or $\mathrm{CD}^{+} \mathrm{T}$ cells that produce more protective cytokines have the potential to develop into memory-type cells [38]. Although most of TB vaccine studies investigate percentage of IFN $-\gamma^{+} \mathrm{CD}^{+}$or $\mathrm{CD}^{+} \mathrm{T}$ cell populations, it has been shown that IFN- $\gamma$ alone is not sufficient for long-lived protection [39]. In this regard, our 
designed LC3-fused multi-epitope DNA construct remarkably induced a $\mathrm{CD} 4^{+} \mathrm{T}$ cell population that expresses IFN- $\gamma$ and IL-2, simultaneously. The IFN- $\gamma^{+}$IL- $2^{+}$ $\mathrm{CD}^{+} \mathrm{T}$ cell population may qualify this proposed construct as effective by its ability to create memory cells in a long-lived protective manner. Also, the multiepitope DNA construct induced high level of IFN- $\gamma^{+} \mathrm{IL}-2^{+} \mathrm{CD} 4^{+} \mathrm{T}$ cell response, but this was significantly less than LC3-fused DNA construct.

IL-10 is an anti-inflammatory cytokine produced by various immune cells, but IL-10 produced by effector T cells restricts the immune response [40]. IL-4 is a classical Th2 and Tc2 cytokine which downregulates the Th1 immune response and increases in active TB disease [41, 42]. Various studies showed that IL-4 and IL-10 limit the efficacy of vaccines [43-46]. Therefore, an effectively designed vaccine may not induce IL-10 and IL-4 cytokines [47, 48]. In our study, DNA constructs with or without fusion of LC3 did not elicit either IL-4 or IL-10 from $\mathrm{CD}^{+}$and $\mathrm{CD} 8^{+} \mathrm{T}$ cell populations, which show the effectiveness of designed DNA constructs. Interestingly, our data indicated that fusion of LC3 resulted in an increase in Th1 but not increase in Th2 suppressive response. This may be due to regulation of autophagy by immune responses through promotion of Th1 and inhibition of Th2 [49]. In contrast, our results showed that BCG highly induced IL-10-producing $\mathrm{CD}^{+} \mathrm{T}$ cell response. Previous studies have indicated that following $\mathrm{BCG}$ vaccination, IL-10 with the role of negative regulatory has reduced the Th1 immune response [50]. Thus, our DNA constructs with no significant induction of IL-10 is more beneficial than BCG.

\section{Conclusions}

LC3-fused multi-epitope DNA construct induced high level of $\mathrm{CD}^{+}$Th1 immune response with an increase in IFN- $\gamma^{+}$and IL- $2^{+} \mathrm{CD} 4^{+} \mathrm{T}$ cell population alongside high potent $\mathrm{CD} 8^{+} \mathrm{Tc} 1$ immune responses with increase in IFN- $\gamma^{+} \mathrm{CD} 8^{+}$ $\mathrm{T}$ cell population. The construct without fusion of LC3 could not induce $\mathrm{IL}-2^{+} \mathrm{CD} 4^{+} \mathrm{T}$ cell population. Also, the LC3-fused construct induced IFN- $\gamma^{+}$ $\mathrm{IL}-2^{+} \mathrm{CD}^{+} \mathrm{T}$ cell population much higher than the construct without LC3. Overall, our data show that fusion of LC3 is more likely to elicit potent Th1 immune response with trends to long-lived immune responses by induction of IL$2^{+} \mathrm{CD}^{+}$and IFN- $\gamma^{+} \mathrm{IL}-2^{+} \mathrm{CD} 4^{+} \mathrm{T}$ cell populations. Since the potency of a DNA vaccine relies on absence of induction of specific $\mathrm{Th} 2$ and $\mathrm{Tc} 2$ immune responses, our results showed that LC3-fused multi-epitope DNA construct did not induce these types of immune responses. According to our results, fusion of LC3 has no effect on induction of suppressive $\mathrm{CD} 4^{+} \mathrm{Th} 2$ responses, so it may be an effective strategy to increase protective $\mathrm{CD} 4^{+} \mathrm{Th} 1$ immune responses. Finally, 
the LC3-fused multi-epitope DNA construct has a potential as a valuable candidate to be investigated to examine its protective potency and efficacy in the murine TB challenge model.

\section{Acknowledgements}

This work was co-supported by Tehran University of Medical Sciences (grant no. 93-04-30-26221) and the Iran National Science Foundation (grant no. 93021686).

\section{Conflict of Interest}

The authors declare no conflict of interest.

\section{References}

1. Dheda, K., Barry, C. E., 3rd, Maartens, G.: Tuberculosis. Lancet 387, 1211-1226 (2016).

2. World Health Organization: Global Tuberculosis Report 2016. WHO, Geneva, 2016.

3. Nguipdop-Djomo, P., Heldal, E., Rodrigues, L. C., Abubakar, I., Mangtani, P.: Duration of BCG protection against tuberculosis and change in effectiveness with time since vaccination in Norway: A retrospective population-based cohort study. Lancet Infect Dis 16, 219 226 (2016).

4. Principi, N., Esposito, S.: The present and future of tuberculosis vaccinations. Tuberculosis (Edinb) 95, 6-13 (2015).

5. Glaziou, P., Sismanidis, C., Floyd, K., Raviglione, M.: Global epidemiology of tuberculosis. Cold Spring Harb Perspect Med 5, a017798 (2015).

6. Henao-Tamayo, M., Palaniswamy, G. S., Smith, E. E., Shanley, C. A., Wang, B., Orme, I. M., Basaraba, R. J., DuTeau, N. M., Ordway, D.: Post-exposure vaccination against Mycobacterium tuberculosis. Tuberculosis (Edinb) 89, 142-148 (2009).

7. Husain, A. A., Daginawala, H. F., Singh, L., Kashyap, R. S.: Current perspective in tuberculosis vaccine development for high TB endemic regions. Tuberculosis (Edinb) $\mathbf{9 8 ,}$ 149-158 (2016).

8. Voskuil, M. I., Schnappinger, D., Visconti, K. C., Harrell, M. I., Dolganov, G. M., Sherman, D. R., Schoolnik, G. K.: Inhibition of respiration by nitric oxide induces a Mycobacterium tuberculosis dormancy program. J Exp Med 198, 705-713 (2003).

9. Rustad, T. R., Harrell, M. I., Liao, R., Sherman, D. R.: The enduring hypoxic response of Mycobacterium tuberculosis. PLoS One 3, e1502 (2008).

10. Singh, S., Saraav, I., Sharma, S.: Immunogenic potential of latency associated antigens against Mycobacterium tuberculosis. Vaccine 32, 712-716 (2014).

11. Roupie, V., Romano, M., Zhang, L., Korf, H., Lin, M. Y., Franken, K. L., Ottenhoff, T. H., Klein, M. R., Huygen, K.: Immunogenicity of eight dormancy regulon-encoded proteins of 
Mycobacterium tuberculosis in DNA-vaccinated and tuberculosis-infected mice. Infect Immun 75, 941-949 (2007).

12. Chauhan, P., Jain, R., Dey, B., Tyagi, A. K.: Adjunctive immunotherapy with $\alpha$-crystallin based DNA vaccination reduces Tuberculosis chemotherapy period in chronically infected mice. Sci Rep 3, 1821 (2013).

13. Commandeur, S., Lin, M. Y., van Meijgaarden, K. E., Friggen, A. H., Franken, K. L., Drijfhout, J. W., Korsvold, G. E., Oftung, F., Geluk, A., Ottenhoff, T. H.: Double- and monofunctional CD4(+) and CD8(+) T-cell responses to Mycobacterium tuberculosis DosR antigens and peptides in long-term latently infected individuals. Eur J Immunol 41, 2925-2936 (2011).

14. Pathan, A. A., Wilkinson, K. A., Klenerman, P., McShane, H., Davidson, R. N., Pasvol, G., Hill, A. V., Lalvani, A.: Direct ex vivo analysis of antigen-specific IFN-gamma-secreting CD4 T cells in Mycobacterium tuberculosis-infected individuals: Associations with clinical disease state and effect of treatment. J Immunol 167, 5217-5225 (2001).

15. Behar, S. M., Woodworth, J. S., Wu, Y.: Next generation: Tuberculosis vaccines that elicit protective CD8+ T cells. Expert Rev Vaccines 6, 441-456 (2007).

16. van Pinxteren, L. A., Cassidy, J. P., Smedegaard, B. H., Agger, E. M., Andersen, P.: Control of latent Mycobacterium tuberculosis infection is dependent on CD8 T cells. Eur J Immunol 30, 3689-3698 (2000).

17. Flynn, J. L., Chan, J.: Immunology of tuberculosis. Annu Rev Immunol 19, 93-129 (2001).

18. Gutierrez, M. G., Master, S. S., Singh, S. B., Taylor, G. A., Colombo, M. I., Deretic, V.: Autophagy is a defense mechanism inhibiting BCG and Mycobacterium tuberculosis survival in infected macrophages. Cell 119, 753-766 (2004).

19. Munz, C.: Antigen processing for MHC class II presentation via autophagy. Front Immunol 3, 9 (2012).

20. Itakura, E., Kishi-Itakura, C., Mizushima, N.: The hairpin-type tail-anchored SNARE syntaxin 17 targets to autophagosomes for fusion with endosomes/lysosomes. Cell 151, 1256-1269 (2012).

21. Munz, C.: Antigen processing via autophagy - Not only for MHC class II presentation anymore? Curr Opin Immunol 22, 89-93 (2010).

22. Moradi, J., Tabrizi, M., Izad, M., Mosavari, N., Feizabadi, M.M.: Designing a novel multiepitope DNA based vaccine against tuberculosis: In silico approach. Jundishapur J Microbiol 10, e43950 (2017).

23. Ernst, J. D.: The immunological life cycle of tuberculosis. Nat Rev Immunol 12, 581-591 (2012).

24. Bruffaerts, N., Huygen, K., Romano, M.: DNA vaccines against tuberculosis. Expert Opin Biol Ther 14, 1801-1813 (2014).

25. Smahel, M., Polakova, I., Duskova, M., Ludvikova, V., Kastankova, I.: The effect of helper epitopes and cellular localization of an antigen on the outcome of gene gun DNA immunization. Gene Ther 21, 225-232 (2014).

26. Guapillo, C., Hernandez-Pando, R., Flores-Valdez, M. A.: Multiantigenic subunitary vaccines against tuberculosis in clinical trials: Where do we stand and where do we need to go? Hum Vaccin Immunother 12, 1193-1195 (2016).

27. Chaitra, M. G., Shaila, M. S., Nayak, R.: Characterization of T-cell immunogenicity of two PE/PPE proteins of Mycobacterium tuberculosis. J Med Microbiol 57, 1079-1086 (2008). 
28. Lunemann, J. D., Munz, C.: Autophagy in CD4+ T-cell immunity and tolerance. Cell Death Differ 16, 79-86 (2009).

29. Jasenosky, L. D., Scriba, T. J., Hanekom, W. A., Goldfeld, A. E.: T cells and adaptive immunity to Mycobacterium tuberculosis in humans. Immunol Rev 264, 74-87 (2015).

30. Flynn, J. L., Chan, J., Triebold, K. J., Dalton, D. K., Stewart, T. A., Bloom, B. R.: An essential role for interferon gamma in resistance to Mycobacterium tuberculosis infection. $\mathrm{J}$ Exp Med 178, 2249-2254 (1993).

31. Hu, H., Huston, G., Duso, D., Lepak, N., Roman, E., Swain, S. L.: CD4(+) T cell effectors can become memory cells with high efficiency and without further division. Nat Immunol 2 , 705-710 (2001).

32. Sarkar, S., Kalia, V., Haining, W. N., Konieczny, B. T., Subramaniam, S., Ahmed, R.: Functional and genomic profiling of effector CD8 $\mathrm{T}$ cell subsets with distinct memory fates. J Exp Med 205, 625-640 (2008).

33. Millington, K. A., Innes, J. A., Hackforth, S., Hinks, T. S., Deeks, J. J., Dosanjh, D. P., Guyot-Revol, V., Gunatheesan, R., Klenerman, P., Lalvani, A.: Dynamic relationship between IFN-gamma and IL-2 profile of Mycobacterium tuberculosis-specific T cells and antigen load. J Immunol 178, 5217-5226 (2007).

34. Day, C. L., Mkhwanazi, N., Reddy, S., Mncube, Z., van der Stok, M., Klenerman, P., Walker, B. D.: Detection of polyfunctional Mycobacterium tuberculosis-specific T cells and association with viral load in HIV-1-infected persons. J Infect Dis 197, 990-999 (2008).

35. Lin, M. Y., Geluk, A., Smith, S. G., Stewart, A. L., Friggen, A. H., Franken, K. L., Verduyn, M. J., van Meijgaarden, K. E., Voskuil, M. I., Dockrell, H. M., Huygen, K., Ottenhoff, T. H., Klein, M. R.: Lack of immune responses to Mycobacterium tuberculosis DosR regulon proteins following Mycobacterium bovis BCG vaccination. Infect Immun $\mathbf{7 5}$, 3523-3530 (2007).

36. Openshaw, P., Murphy, E. E., Hosken, N. A., Maino, V., Davis, K., Murphy, K., O'Garra, A.: Heterogeneity of intracellular cytokine synthesis at the single-cell level in polarized $\mathrm{T}$ helper 1 and T helper 2 populations. J Exp Med 182, 1357-1367 (1995).

37. Wu, C. Y., Kirman, J. R., Rotte, M. J., Davey, D. F., Perfetto, S. P., Rhee, E. G., Freidag, B. L., Hill, B. J., Douek, D. C., Seder, R. A.: Distinct lineages of T(H)1 cells have differential capacities for memory cell generation in vivo. Nat Immunol 3, 852-858 (2002).

38. Stockinger, B., Bourgeois, C., Kassiotis, G.: CD4+ memory T cells: Functional differentiation and homeostasis. Immunol Rev 211, 39-48 (2006).

39. Kagina, B. M., Abel, B., Scriba, T. J., Hughes, E. J., Keyser, A., Soares, A., Gamieldien, H., Sidibana, M., Hatherill, M., Gelderbloem, S., Mahomed, H., Hawkridge, A., Hussey, G., Kaplan, G., Hanekom, W. A.: Specific T cell frequency and cytokine expression profile do not correlate with protection against tuberculosis after bacillus Calmette-Guerin vaccination of newborns. Am J Respir Crit Care Med 182, 1073-1079 (2010).

40. Couper, K. N., Blount, D. G., Riley, E. M.: IL-10: The master regulator of immunity to infection. J Immunol 180, 5771-5777 (2008).

41. Biedermann, T., Zimmermann, S., Himmelrich, H., Gumy, A., Egeter, O., Sakrauski, A. K., Seegmuller, I., Voigt, H., Launois, P., Levine, A. D., Wagner, H., Heeg, K., Louis, J. A., Rocken, M.: IL-4 instructs TH1 responses and resistance to Leishmania major in susceptible BALB/c mice. Nat Immunol 2, 1054-1060 (2001). 
42. Smith, S. M., Klein, M. R., Malin, A. S., Sillah, J., McAdam, K. P., Dockrell, H. M.: Decreased IFN-gamma and increased IL-4 production by human CD8(+) T cells in response to Mycobacterium tuberculosis in tuberculosis patients. Tuberculosis (Edinb) 82, 7-13 (2002).

43. Rook, G. A., Hernandez-Pando, R., Dheda, K., Teng Seah, G.: IL-4 in tuberculosis: Implications for vaccine design. Trends Immunol 25, 483-488 (2004).

44. Lowrie, D. B., Tascon, R. E., Bonato, V. L., Lima, V. M., Faccioli, L. H., Stavropoulos, E., Colston, M. J., Hewinson, R. G., Moelling, K., Silva, C. L.: Therapy of tuberculosis in mice by DNA vaccination. Nature 400, 269-271 (1999).

45. Silva, R. A., Pais, T. F., Appelberg, R.: Blocking the receptor for IL-10 improves antimycobacterial chemotherapy and vaccination. J Immunol 167, 1535-1541 (2001).

46. Redford, P. S., Murray, P. J., O'Garra, A.: The role of IL-10 in immune regulation during M. tuberculosis infection. Mucosal Immunol 4, 261-270 (2011).

47. Boussiotis, V. A., Tsai, E. Y., Yunis, E. J., Thim, S., Delgado, J. C., Dascher, C. C., Berezovskaya, A., Rousset, D., Reynes, J. M., Goldfeld, A. E.: IL-10-producing T cells suppress immune responses in anergic tuberculosis patients. J Clin Invest 105, 1317-1325 (2000).

48. Brooks, D. G., Lee, A. M., Elsaesser, H., McGavern, D. B., Oldstone, M. B.: IL-10 blockade facilitates DNA vaccine-induced $\mathrm{T}$ cell responses and enhances clearance of persistent virus infection. J Exp Med 205, 533-541 (2008).

49. Harris, J., Master, S. S., De Haro, S. A., Delgado, M., Roberts, E. A., Hope, J. C., Keane, J., Deretic, V.: Th1-Th2 polarisation and autophagy in the control of intracellular mycobacteria by macrophages. Vet Immunol Immunopathol 128, 37-43 (2009).

50. Pitt, J. M., Stavropoulos, E., Redford, P. S., Beebe, A. M., Bancroft, G. J., Young, D. B., O'Garra, A.: Blockade of IL-10 signaling during bacillus Calmette-Guerin vaccination enhances and sustains Th1, Th17, and innate lymphoid IFN-gamma and IL-17 responses and increases protection to Mycobacterium tuberculosis infection. J Immunol 189, 40794087 (2012). 